\title{
ODA A WALT WHITMAN: HOMENAJE DE GARCÍA LORCA AL POETA DEL PUEBLO Y LAS MULTITUDES
}

\author{
Dorde Cuvardic García
}

\begin{abstract}
RESUMEN
La Oda a Walt Whitman es un homenaje de Federico García Lorca al poeta de la multitud, del amor universal, de la democracia. Frente a la ciudad deshumanizada, en este caso Nueva York, el poeta granadino anhela una sociedad solidaria cuyo modelo más cercano es el autor de Hojas de hierba. Este poema se interpreta desde su pertenencia genérica, la oda, desde la interpelación del apóstrofe, dirigida al poeta estadounidense, y desde las implicaciones estilísticas de la representación de la metrópoli en el surrealismo.

Palabras clave: Poesía surrealista, poesía urbana, representación de la ciudad.
\end{abstract}

\begin{abstract}
An Oda a Walt Whitman is an homage Federico García Lorca to the poet of the masses, of universal love, of democracy. Confronting the dehumanizing city, in this case New York, the poet from Granada yearns for a society of solidarity whose most accessible model is this author of Hojas de hierba. This poem may be interpreted from its generic relevance, the ode, from the question of the apostrophe as used by this United States poet and from the stylistic implications of the representation of the metropolis surrealistically.

Key words: surrealistic poet, urban poetry, representation of the city.
\end{abstract}

1.

La Oda a Walt Whitman, de la Sección VIII (Dos odas) de Poeta en Nueva York, representa un homenaje de Federico García Lorca al gran bardo de Nueva York, al creador de Hojas de hierba, uno de los más importantes poemas urbanos de la modernidad cultural.

La función de la oda ha sido, desde la antigüedad grecolatina, elogiar personas, acciones, países, objetos... ${ }^{1}$ Si bien, como otros géneros poéticos, ha servido en el segundo y tercer tercio del siglo XX para ensalzar lo cotidiano, lo rutinario -es preciso recordar las odas

Dorde Cuvardic García. Profesor de la Escuela de Filología, Lingüística y Literatura, Universidad de Costa Rica San Pedro, San José, Costa Rica.

Correo electrónico: dcuvardic@yahoo.es

Recepción: 14- 11- 2006

Aceptación: 30- 3- 2007 
que Pablo Neruda dirigirá a la cebolla, el tomate o la alcachofa en sus Odas elementales-, desde la Antigüedad hasta el primer tercio del siglo pasado, en cambio, sirvió para rendir homenaje, ensalzar o elogiar a todo aquello considerado noble y heroico (en el ámbito de los comportamientos humanos) o poderoso (la Naturaleza y la Idea de Dios). García Lorca utiliza la oda en su función tradicional: homenajear a un poeta con el que comparte una misma ética. Calviño Iglesias (1986: 538), al respecto, considera que predomina en este poema de Poeta en Nueva York una visión apologética, encomiástica y panegírica del escritor estadounidense, desplegada en el adverso contexto capitalista neoyorquino, mediatizado por la oposición autenticidad/ inautenticidad.

Es preciso destacar que el yo-lírico elogia a Whitman desde un espacio neoyorquino caracterizado por la alineación colectiva, mientras que el poeta estadounidense elogió este contexto urbano como espacio democrático y solidario. Las condiciones habían cambiado. García Lorca escribe desde un presente en el que repercuten las consecuencias de la Gran Depresión de 1929.

¿Por qué elogia el yo-lírico al poeta estadounidense? El yo-lírico de Hojas de hierba asume la ciudad como paradigma de una sociedad democrática (Chaffin 1977: 120) caracterizada por el establecimiento de relaciones afectivas entre desconocidos. Asume Nueva York como espacio de hermandad, camaradería, progreso, vitalidad, un ideal utópico para el yo-lírico de Poeta en Nueva York, que considera la urbe estadounidense, en el presente de la enunciación, como espacio de inautenticidad, de egoísmo, de explotación.

García Lorca y Whitman no comparten sólo unas mismas aspiraciones éticas. Otro punto de contacto se encuentra en los procedimientos poéticos descriptivos asumidos por ambos escritores. Un ejemplo es la mirada panorámica. Whitman va individualizando las acciones de los ciudadanos en el espacio público de la calle a partir de una mirada inicialmente panorámica. Por su parte, García Lorca también emprenderá este proceso de individualización en las cinco primeras estrofas de la Oda, aplicado esta vez sobre los trabajadores explotados por el capitalismo, inmersos en la ciudad industrial, totalmente ajenos a la existencia de una naturaleza liberadora ${ }^{2}$. Reproduzco las dos primeras estrofas:

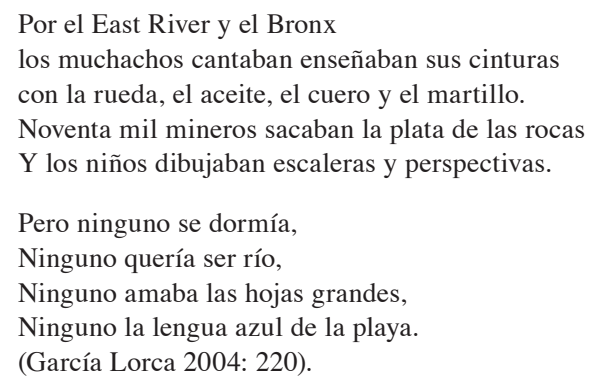

Estos dos párrafos nos describen la alienación de los trabajadores neoyorquinos en la civilización industrial.

Zarobilla (1979) ha demostrado que Walt Whitman, tanto en su prosa como en su poesía, incorporó los principios descriptivos típicos de la mirada panorámica, tal como la desarrollaron los panoramas pictóricos, espectáculo muy popular en las metrópolis occidentales a mediados del siglo XIX. Pero la mirada panorámica sobre la ciudad no sólo es exclusiva de Whitman, sino de muchísimas representaciones literarias de la ciudad en los siglos XIX y $\mathrm{XX}^{3}$. En este sentido, García Lorca no asume necesariamente del poeta estadounidense esta 
convención descriptiva. Debe afirmarse, más bien, que ambos utilizan una misma convención cultural vigente en todas las artes occidentales desde inicios del siglos XIX.

Muchos críticos se han acercado a la propuesta surrealista de Poeta en Nueva York. García-Posada (1981) ha realizado un estudio completo, desde los ámbitos temático, simbólico, métrico, morfológico y sintáctico, fonoestilístico, gráfico, estructural y enunciativo. Calviño Iglesias (1986) también ha realizado un análisis temático, en su caso poema por poema. McMullan (1996) identifica el pensamiento ambivalente de Le Corbusier hacia la ciudad americana en el García Lorca de Poeta en Nueva York. Stone (2000) retrata la presencia flamenca en el poemario. McKinlay (2001) lo ha analizado como ejemplo de arte deshumanizado, desde el pensamiento de Ortega y Gasset. En el ámbito del análisis de poemas específicos, Cruz (1995) ha analizado la presencia de la tradición de la danza de la muerte en Poeta en Nueva York ${ }^{4}$.

La Oda a Walt Whitman también ha recibido bastante atención crítica. Millán (2003) considera las dos odas de la Sección VIII como reflexiones sobre el amor; Grito hacia Roma se ocupa de la falta de solidaridad humana en la ciudad; mientras que en Oda a Walt Whitman el yo-lírico alaba al poeta que cantó, frente a la degradación urbana, a la autenticidad del amor. Havard (2000), por su parte, destaca el carácter profético de este poema, junto con otros de Poeta en Nueva York (se centra en los versos finales del la oda, en "Quiero que el aire fuerte de la noche más honda /quite flores y letras del arco donde duermes / y un niño negro anuncie a los blancos del oro /la llegada del reino de la espiga."): el yo-lírico, al igual que han hecho otros poetas, realiza un retiro (tematizado en las secciones centrales del poemario) y regresa a la ciudad para ofrecer promesas de liberación y de regreso a la naturaleza; este crítico, incluso, considera que García Lorca utiliza en este y en otros poemas la misma estructura rítmica característica de la poesía profética.

Diversos críticos se han ocupado de las oposiciones semánticas que operan en la Oda a Walt Whitman, en cuyo marco la figura bárdica y profética de Whitman vendría a ocupar las valencias positivas. Calviño Iglesias (1986: 538-9) establece las siguientes oposiciones semánticas: condición sexual alienada frente a condición asumida; ética del maquinismo acumulativo frente a ética del goce; razón tecnológica frente a la razón vital que cuestiona moralmente la civilización mercantilizada.

La condición sexual alienada (heterosexual u homosexual) es aquella que sólo recurre al sexo, sin desarrollar ningún sentimiento afectivo. El yo-lírico critica esta condición, desde la denuncia del profeta, en los siguientes versos:

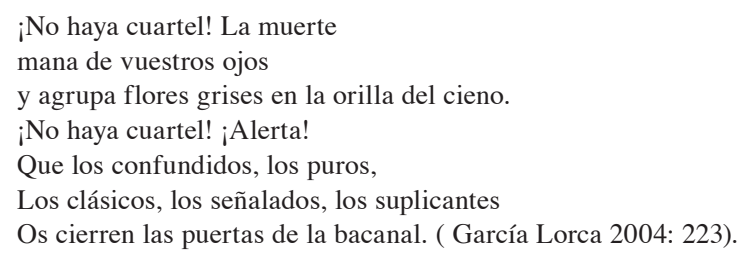

Asimismo, la ética del maquinismo acumulativo se manifiesta en el egoísmo de la acumulación capitalista (razón tecnológica):

Nueva York de cieno,

Nueva York de alambre y de muerte (García Lorca 2004: 220).

Agonía, agonía, sueño, fermento y sueño.

Este es el mundo, amigo, agonía, agonía. 
Los muertos se descomponen bajo el reloj de las ciudades.

La guerra pasa llorando con un millón de ratas grises,

Los ricos dan a sus queridas

Pequeños moribundos iluminados,

Y la vida no es noble, ni buena, ni sagrada. (García Lorca 2004: 222).

La ciudad-máquina produce, asimismo, individuos alienados, totalmente ajenos a la libertad de la vida natural:

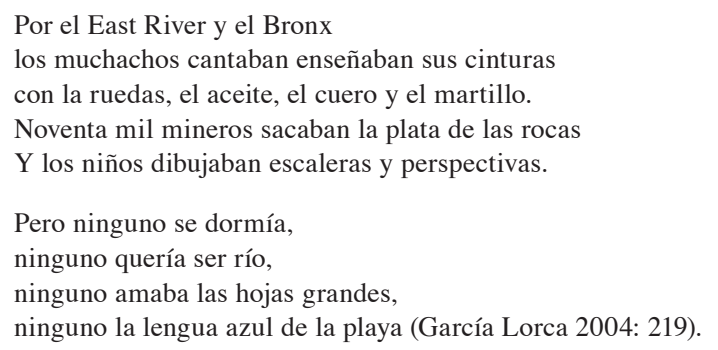

La figura del paseante urbano observador, reflexivo, de la Oda a Walt Whitman ofrecerá dos imágenes de la ciudad: la ciudad-máquina, dominada económicamente por la industrialización, y la ciudad-organismo en estado de descomposición, dominada socialmente por la anomia (la Nueva York de García Lorca recuerda, en su degradación moral, al poema Londres, del poeta visionario romántico William Blake). Mientras que el flaneur del artículo de costumbres decimonónico celebra el consumo de la ciudad bazar, el flaneur-poeta de la Oda a Walt Whitman, así como el resto de la literatura urbana de las vanguardias, denunciará cualquier forma de mercantilización de las relaciones humanas.

\section{Walt Whitman: Modelo de poesía urbana para García Lorca}

El elogio del poeta norteamericano no sólo se realiza desde el discurso verbal sino también desde el icónico. Lorca tenía la intención de ilustrar con fotomontajes los poemas, una vez que llegara a publicarse Poeta en Nueva York. Es muy posible que la el "Fotomontaje de la cabeza de Walt Whitman con la barba llena de mariposas", preparado por García Lorca, llegara a ilustrar el poema que nos ocupa en este artículo. Podríamos considerar la relación entre el paratexto del fotomontaje y parte de la Oda a Walt Whitman que lo describe como un caso de écfrasis, ya que en el discurso verbal del poema se 'muestra', desde el discurso verbal, el fotomontaje preparado por García Lorca: "Ni un solo momento, viejo hermoso Walt Whitman, he dejado de ver tu barba llena de mariposas". La descripción prosopográfica ofrecida en el discurso verbal del poema y en el paratexto del fotomontaje permite perfilar la etopeya del poeta estadounidense: a través de su descripción física, el lector infiere la propuesta ética de su poesía, caracterizada por la búsqueda de unión afectiva entre los ciudadanos de las urbes.

García Lorca emplea procedimientos usados por la poesía urbana desde el siglo XIX, asimismo utilizados por el poeta norteamericano. Las figuras de dicción, en los ámbitos de la repetición y de la amplificación, estructuran sintagmáticamente la Oda a Walt Whitman. Como figuras de repetición aparecen constantemente el paralelismo y la anáfora, cuya función semántica es insistir en la denuncia del yo-lírico. Como figura de amplificación aparece la enumeración caótica, tan común en la poesía urbana para representar el caos o la vitalidad de este espacio humano, procedimiento estilístico que, por otra parte, ya encontró Leo Spitzer en la misma poesía de Walt Whitman en Lingüística e historia literaria. Las figuras retóricas 
mencionadas tienen por función concretar una imagen personal de la ciudad, aquella originada en la perspectiva enunciativa del poema.

También cumple función principal en el poema que comentamos el apóstrofe, recurso bastante utilizado en la oda, género desde el que se procura homenajear a alguien ausente mediante una interpelación que simula su presencia frente al yo-lírico ${ }^{5}$. Mientras que en la parte final del poema la perspectiva enunciativa realiza una serie de imprecaciones a aquellas personas que practican una visión exclusivamente carnal de la sexualidad, en cambio dirige en la primera mitad del poema apóstrofes laudatorios a Whitman, a quien considera cantor de una visión espiritual de la sexualidad, con independencia de su orientación 6 . Lorca elogia a Whitman por ensalzar la opción espiritual de la expresión homosexual. Por contraste, critica su dimensión exclusivamente física, ajena a la afectividad. Precisamente uno de los atributos del profeta es la denuncia de una situación presente caracterizada por la ausencia de relaciones afectivas, por el predominio de relaciones exclusivamente mercantiles. $\mathrm{Su}$ actitud complementaria es proponer, como alternativa, una situación futura positiva. Lorca considera que la posibilidad utópica de un mundo caracterizado por el amor se encuentra en el pensamiento solidario de Whitman.

El rasgo que García Lorca ensalza es la capacidad que tiene el poeta norteamericano de definir una imaginaria relación homoerótica de carácter espiritual a partir de la exaltación del transeúnte, a veces a través del encuentro de miradas entre este último y el poeta, tema muy destacado por los críticos del poeta estadounidense. Algo que también hizo Baudelaire con el encuentro heterosexual en su espléndido $A$ une passante (A una transeúnte), poema que tematiza un fugaz amor a primera vista entre el poeta-flâneur y una joven viuda (encuentro muy utilizado por los poetas románticos -Bécquer en una de sus Rimas-, o por los narradores decadentistas, como el José Martínez Ruíz de Diario de un enfermo). García Lorca admira en Whitman su capacidad para convertir el encuentro con un extraño en un acto caracterizado por la solidaridad 7 , actitud que asumirá García Lorca en Poeta en Nueva York con los negros, los gitanos y los homosexuales.

El apóstrofe al poeta ausente permea la primera parte del poema. Pero el yo-lírico no sólo se dirige, como si estuviera presente, a Walt Whitman. No sólo se incorpora al escritor estadounidense en la interpelación producida por el enunciador (se establece un simulacro de circuito comunicativo entre ambos poetas), sino que también se hace presente el cuerpo de este destinatario. Como procedimiento visionario, la instancia enunciativa hace presente el cuerpo de Walt Whitman mediante el procedimiento descriptivo de la hipotiposis, utilizado en algunos versos de la oda. La aspectualización física del poeta estadounidense, su retrato etopéyico, su conversión en figura ucrónica (en lugar de histórica) o su descripción metaforizada mediante el empleo de la semántica de la Naturaleza son recursos que, según Calviño Iglesias (1986: 539), sirven para construir en este poema la hipérbole laudatoria de Walt Whitman:

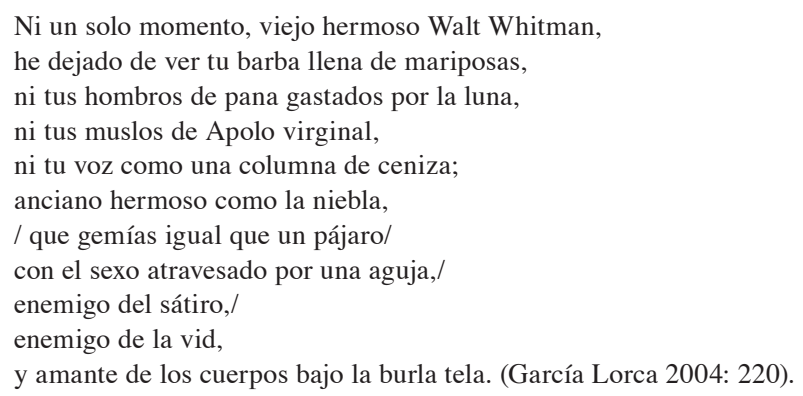


Este es un momento de unión simbólica: el yo-lírico, en lugar de tener conciencia de la imposibilidad de establecer un vínculo comunicativo con Walt Whitman (situación alegórica), supera este desfase temporal mediante el apóstrofe y la hipotiposis (situación simbólica), momento de comunicación, y de identidad de intereses, con el sujeto elogiado.

Una de las funciones del apóstrofe es definir el encuentro entre el yo-lírico y el mundo como una relación entre dos sujetos (y no ya como una relación entre el sujeto enunciativo y un objeto -la realidad externa-) (Culler 2001). Mediante el apóstrofe, el yo-lírico convierte a Walt Whitman, referente histórico, poeta canónico de la historia literaria (objeto), en un tú presente con el que entra en relación comunicativa y afectiva (sujeto). Con el uso de este recurso, el yo-lírico convierte en sujeto participante de un diálogo o conversación a un referente que, gracias a la enunciación poética, deja de ser objeto, es decir, un ente externo sin atributos vitales. En otros casos el sujeto interpelado del apóstrofe será el recuerdo de la amada, una idea o un objeto de la naturaleza, pero en el poema que nos ocupa el sujeto de la interpelación es un poeta apreciado por la ética solidaria de su práctica literaria.

El apóstrofe también permite que la presencia del tiempo discursivo o enunciativo desplace al del tiempo empírico (Culler 2001: 165). Frente a la temporalidad histórica o referencial, el poema en el que impera el apóstrofe se caracteriza por el presente de la enunciación del yo-lírico. En el tiempo empírico, histórico, García Lorca y Walt Whitman no podían, en ningún caso, comunicarse. Lorca visitó Nueva York en 1929-30, mientras que el poeta estadounidense murió en 1892. Sin embargo, el ahora producido por el tiempo discursivo o enunciativo del apóstrofe permite actualizar un encuentro discursivo imaginario entre el yo-lírico y Whitman. El enunciador elogia al poeta estadounidense e invoca la capacidad que tuvo de establecer, mediante la palabra poética, un vínculo amoroso universal con los ciudadanos interpelados en sus poemas. Para García Carreño (1986: 540), el apóstrofe dirigido al poeta estadounidense sacraliza su figura como demiurgo del amor no contaminado; mediante este recurso poético, queda retratado (barba, manos abiertas, arcilla, lengua) desde atributos mesiánicos, proféticos, despojado de toda caracterización materialista. Precisamente el yo-lírico admira del poeta norteamericano la capacidad para superar la alineación urbana de Nueva York en las situaciones comunicativas imaginativas creadas en sus poemas. Ahora bien, desde el presente dominado por la depresión económica de 1929, Lorca sólo comprende la espiritualidad colectiva como posibilidad visionaria, como ideal futuro.

El poeta también apostrofa para convertirse en espectáculo de sí mismo, para convertirse, ante el lector, en un poeta capaz de invocar exitosamente a los objetos hasta tal grado que estos últimos podrían, a su vez, responderle (Culler 1981). En este sentido, el yo-lírico de la Oda a Walt Whitman tiene la pretensión de ser equiparado por el lector al poeta estadounidense. Una vez repuesto de su crisis vocacional y de su desengaño amoroso ${ }^{8}$, el yo-lírico también quiere ser reconocido, como lo fue en su tiempo Walt Whitman, como el poeta profético y visionario que augura la disolución de la anomia urbana (de la incomunicación entre los habitantes de la metrópoli), y el surgimiento de una nueva época de amor colectivo. 


\section{Conclusión}

La mejor escritura surrealista de la Generación del 27 se origina en crisis afectivas. En Poeta en Nueva York, de Lorca; Un río, Un amor, de Cernuda; y Sobre los ángeles, de Alberti, se tematiza el desengaño amoroso.

En el caso específico de Poeta en Nueva York, una vez superada su crisis, expuesta en las secciones centrales del poemario, el yo-lírico regresa a la metrópoli. Es entonces cuando lanza la denuncia social de la Sección VII, Vuelta a la ciudad-Nueva York, Oficina y denuncia; Cementerio judio; Crucifixión- y de la Sección VIII, Dos odas -Grito hacia Roma (Desde la Torre del Chrysler Building y Oda a Walt Whitman).

Al tematizar la ciudad de Nueva York desde la denuncia, García Lorca se declara heredero de la ideología humanista del poeta estadounidense. La crítica de la degradación a la que es sometido el 'otro' urbano marginal por la sociedad es una táctica que desde el Romanticismo todo poeta urbano ha venido ejecutando. Un procedimiento simultáneo es alegorizar en estas figuras su propia condición marginal dentro del capitalismo. Recordemos aquellos poemas de la sección Cuadros Parisinos de Las flores del mal, de Baudelaire, dedicados a la búsqueda de empatía con el 'marginado social' (A una mendiga pelirroja, Los siete viejos, Las viejecitas, Los ciegos).

En Oda a Walt Whitman, así como Hojas de Hierba, la perspectiva enunciativa asume un papel recurrente en la poesía urbana desde el siglo XIX: el poeta paseante o poeta flâneur. Una de las facetas más fascinantes del poeta paseante es la empatía o la identificación que proyectará en las personas, y más específicamente en los rostros que individualizará entre la multitud. Tanto el poeta español como el estadounidense construyeron una intimidad y un compromiso imaginarios con los habitantes de la ciudad. En el segundo caso, como afirma Brand (1991: 184), "Whitman trató de convertir la libertad y el poder desplegados por el espectador distanciado de la metrópoli en una nueva forma de experiencia espiritual. En un momento casi místico de unión con las multitudes, o con amantes extraídos de su medio, consideró posible disfrutar de una forma de amor predominantemente visual que pudiera constituirse en la base de un nuevo vínculo social apropiado a las condiciones de la vida urbana". A diferencia del estilo impresionista aplicado por Azorín en muchas de sus representaciones panorámicas, en las que los campesinos son simples manchas del paisaje, la mirada panorámica de Lorca sobre la urbe logra individualizar solidariamente a sus ciudadanos a partir de una táctica de acercamiento, mirada de la que también participa Whitman.

El poeta de Hojas de hierba tematiza la comunión que el poeta establece con los transeúntes, los obreros... En muchos de sus poemas, el yo-lírico construye su identidad al entrar en contacto visual con los ciudadanos, a quienes saluda como sus amantes en la relación afectiva que la mirada ha permitido establecer (Sharpe 1990). La alineación puede ser superada mediante esta comunión afectiva con los extraños. Esta alternativa se propone como posibilidad futura en Poeta en Nueva York: después de los poemas urbanos que tematizan la alineación, la anomia, se sitúan aquellos que expresan la posibilidad de su superación. Mientras que en los primeros poemas su visión de la ciudad es la misma que la compartida por Baudelaire, orientada hacia la pesadilla y la sordidez (no sólo Las flores del mal incorporan una danza macabra, sino también Poeta en Nueva York), en los últimos poemas quiere compartir la visión mesiánica que tiene Whitman sobre la ciudad. En lugar de ser un cementerio (Larra, en El día de difuntos de 1836. Fígaro en el cementerio; Dámaso Alonso en Insomnio), o un desierto de 
hombres (Baudelaire, en El pintor de la vida moderna), la ciudad se convierte en García Lorca en un espacio de comunión solidaria, propuesta que también respaldará el yo-lírico de En la plaza (En un vasto dominio), de Vicente Aleixandre, al interpelarse a sí mismo desde el tú reflexivo: "Baja, baja despacio y búscate entre los otros./ Allí están todos, y tú entre ellos./ Oh, desnúdate y fúndete, y reconócete" (Aleixandre 1997: 200). En las secciones finales de Poeta en Nueva York se ofrecerá la posibilidad de una utopía urbana fundamentada en la solidaridad, ámbito del que participa la Oda a Walt Whitman.

\section{Notas}

1. García Lorca también utilizó este género poético en Oda al Santísimo Sacramento del Altar y en Oda a Salvador Dalí.

2. La crítica al capitalismo se encuentra presente en muchos de los poemas urbanos de Poeta en Nueva York. Otro ejemplo es La aurora.

3. En todo caso, la perspectiva panorámica se utilizó en casi todas las artes decimonónicas. Se aplicó en los artículos de costumbres, en la novela romántica y realista, en la pintura impresionista...

4. Las vanguardias revitalizaron el tema de la danza de la muerte. Por ejemplo, pocos años antes de la escritura de Poeta en Nueva York se usó este motivo cultural en Metrópolis, de Fritz Lang.

5. Recordemos la definición que ofrece Lausberg: "La apóstrofe consiste en «apartarse» del público normal... y dirigir la palabra a otro segundo público elegido por el orador de manera sorprendente. Ello tiene sobre el público normal un efecto patético, pues constituye en el orador la expresión de un pathos que no puede canalizarse por los cauces normales de comunicación entre orador y público. La apóstrofe es, por decirlo así, un paso desesperado por parte del orador, impulsado por el pathos. Como segundo público en la apóstrofe hacen al caso: el contrincante, personas no presentes vivas o muertas, cosas (patria, leyes, heridas, etc.)" (II: 192-93; en La Rubia Prado 2004).

6. García Lorca no ha sido el único poeta que ha homenajeado a Whitman y que lo apostrofa desde la instancia del yo-lírico. Hart Crane hizo lo mismo, curiosamente en la misma época de redacción de Poeta en Nueva York, con su poema épico El puente (1930):

O Saunteter on free ways still ahead!/

Not this our empire yet, but labyrinth/

Wherein your eyes, like the Great Navigator's without

ship,

Gleam from the great stones of each prison crypt

Of canyoned traffic... (citado en Pike 1981: 86).

7. La solidaridad con el 'otro' desconocido encontrará una magnífica reflexión en el poema en prosa Las multitudes, de Baudelaire, excelente ejemplo de teorización en un texto literario:

El poeta goza del incomparable privilegio de poder ser, a su guisa, él mismo y el otro. Como las almas que vagan buscando un cuerpo, entra, cuando quiere, en el personaje de cada uno. (...)/ El pensativo y solitario paseante obtiene una singular embriaguez de esta comunión universal. Quien se desposa fácilmente con la multitud, conoce gozos febriles (...) Abraza como suyas todas las profesiones, todas las alegrías y todas las miserias que la circunstancia le presenta./ Lo que los hombres llaman amor es cosa muy pequeña, restringida y débil, en comparación con esta inefable orgía, con esta santa prostitución del alma que se da por completo, poesía y caridad, a lo que aparece de improviso, a lo desconocido que pasa (Baudelaire 2000: 66). 
8. Los poemas de desengaño amoroso pertenecen a las secciones IV. Poemas del lago Eden Mills, V. En la cabaña del Farmer (Campo de Newburg) y VI. Introducción a la muerte (Poemas de la soledad en Vermont).

\section{Bibliografía}

Aleixandre, Vicente. 1997. "Antología”. Poesía de la Generación del 27. Antología crítica comentada. Madrid: Editorial Edaf.

Baudelaire, Charles. 2000. Pequeños poemas en prosa. Los paraísos artificiales (Edición de José Antonio Millán Alba). Madrid: Editorial Cátedra.

Brand, Dana. 1991. The spectator and the city in nineteenth-century american literature. New York: Cambridge University Press.

Calviño Iglesias, Julio. 1986. "Poeta en Nueva York como mentira metonímica”. Cuadernos hispanoamericanos. 435-36, 519-42.

Cruz, Jacqueline. 1995. "Surrealismo y Edad Media: la 'Danza de la muerte' de Lorca”. Anales de Literatura española contemporánea. 20 (1-2): 65-83.

Chaffin, J. Thomas, Jr. 1977. "Give me faces and streets: Walt Whitman and the city". Walt Whitman Review. 23: 109- 120.

Culler, Jonathan. 1981. The pursuit of signs. Ithaca: Cornell University Press.

Enguídanos, Miguel. 1986. "Del rey de los Gitanos al rey de Harlem: sobre Poeta en Nueva York". Ínsula. 1 y 20.

Flint, Christopher. 1988. "Flesh of the poet: representations of the body in Romancero gitano and Poeta en Nueva York". Papers on Language and Literature. 24: 177- 211. Recuperado el 29 de abril del 2005 de la base de datos EBSCO.

García Lorca, Federico. 2003. Poeta en Nueva York (Edición de María Clementa Millán). Madrid: Editorial Cátedra.

García-Posada, Miguel. 1981. Lorca: interpretación de 'Poeta en Nueva York'. Madrid: Akal editor.

Geist, Anthony L. 1986. "Las mariposas en la barba: una lectura de Poeta en Nueva York". Cuadernos hispanoamericanos. 435-6, 547-65.

Havard, Robert. 2000. "Lorca's mantic poet in New York". Anales de literatura española contemporánea. 25: 439-78. 
La Rubia Prado, Francisco. 2004. Retorno al futuro: amor, muerte y desencanto en el Romanticismo español. Madrid: Editorial Biblioteca Nueva.

López-Casanova, Arcadio. 1994. El texto poético. Teoría y metodología. Salamanca: Ediciones Colegio de España.

McKinlay, Neil C. 2001. "The dehumanization of Poeta en Nueva York". Journal of Iberian and Latin American Studies. 7 (2): 157- 171. Recuperado el 29 de abril del 2005 de la base de datos EBSCO.

McMullan, Terence. 1996. "Federico García Lorca' s Poeta en Nueva York and The city of tomorrow". Bulletin of Hispanic Studies. 73: 65- 79. Recuperado el 29 de abril del 2005 de la base de datos EBSCO.

Millán, María Clementa. 2003. “Introducción y apéndice”. En: Federico García Lorca. Poeta en Nueva York (Edición de María Clementa Millán). Madrid: Editorial Cátedra.

Pike, Burton. 1981. The image of the city in modern literature. Princeton, N.J.: Princeton University Press.

Pineda, Victoria. "La invención de la écfrasis". En: www.fylunex.com/foro/publicaciones/ hcarmen/hcarmen3.pdf. 20 de mayo del 2005.

Sharpe, William Chapman. 1990. Unreal figuration in Wordsworth, Baudelaire, Whitman, Eliot and Williams. Baltimore: John Hopkins University Press.

Sinclair, Alison. "Lorca: Poet in New York". En: Edward Timms y David Kelley (eds.). Unreal city. Urban experience in modern European literature and art. Manchester: University Press.

Spitzer, Leo. 1974. Lingüística e historia literaria. Madrid: Editorial Gredos.

Stone, Rob. 2000. “Quiero llorar': Lorca y la tradición flamenca en Poeta en Nueva York”. Bulletin of Hispanic Studies. 77: 493- 510. Recuperado el 29 de abril del 2005 de la base de datos EBSCO.

Whitman, Walt. 1921. Leaves of grass. New York: The modern library.

Zarobila, Charles. 1979. "Walt Whitman and the panorama". Walt Whitman Review. 25: 51- 9. 